\title{
Effective communication of molecular genetic test results to primary care providers
}

\author{
Maren T. Scheuner, MD, MPH ${ }^{1,2,3}$, Maria Orlando Edelen, $\mathrm{PhD}^{1}$, Lee H. Hilborne, MD, MPH',4,5 and \\ Ira M. Lubin, PhD ${ }^{6}$; for the members of the RAND Molecular Genetic Test Report Advisory Board
}

Purpose: We evaluated a template for molecular genetic test reports that was developed as a strategy to reduce communication errors between the laboratory and ordering clinician.

Methods: We surveyed 1,600 primary care physicians to assess satisfaction, ease of use, and effectiveness of genetic test reports developed using our template and reports developed by clinical laboratories. Mean score differences of responses between the reports were compared using $t$-tests. Two-way analysis of variance evaluated the effect of template versus standard reports and the influence of physician characteristics.

Results: There were 396 (24\%) respondents. Template reports had higher scores than the standard reports for each survey item. The gender and specialty of the physician did not influence scores; however, younger physicians gave higher scores regardless of report type. There was significant interaction between report type and whether physicians ordered or reviewed any genetic tests (none versus at least one) in the past year, $P=0.005$.

Conclusion: For each survey item assessing satisfaction, ease of use, and effectiveness, physicians gave higher ratings to genetic test reports developed with the template than standard reports used by clinical laboratories. Physicians least familiar with genetic test reports, and possibly having the greatest need for better communication, were best served by the template reports.

Genet Med 2013:15(6):444-449

Key Words: communication; genetic testing; molecular genetics; standardized reporting

\section{INTRODUCTION}

Genetic tests are increasingly available for both Mendelian disorders and multifactorial forms of common diseases. Genetic test results have the potential to impact health outcomes by improving our ability to diagnose, treat, and prevent disease. Currently, clinical genetic testing for heritable conditions is generally limited to testing for Mendelian disorders because of limited progress in the discovery of genes for multifactorial disorders that have meaningful clinical relevance. ${ }^{1-4}$

Indications for genetic testing of heritable traits include diagnostic, prognostic, and predictive testing, testing of carrier status for recessive conditions, and testing of therapeutic response (i.e., pharmacogenetic testing). The indication for testing is informed by patient demographic information, medical history, and family health history. For example, diagnostic genetic testing is performed when a Mendelian disorder or heritable risk is suspected on the basis of signs or symptoms; carrier screening is performed in asymptomatic individuals with reproductive risks due to their ancestry or family history; and predictive testing is performed in asymptomatic individuals at risk for disease due to a family history suggestive of a Mendelian disorder of high penetrance (presymptomatic testing) or reduced penetrance (predisposition testing).
Interpreting results of genetic testing is complex and depends on the context related to the indication for testing. Furthermore, any particular indication for genetic testing can depend on the intended use of the test result. For example, diagnostic testing in a patient with signs and symptoms of disease may be performed primarily for medical decision making, yet it may also inform a patient's reproductive or life-planning decisions. Therefore, effective communication between the genetic testing laboratory and ordering clinician is essential for optimal test utilization and interpretation. ${ }^{5-8}$

Unfortunately, clinicians frequently have difficulty understanding the implications of genetic tests results, ${ }^{9-13}$ and they express dissatisfaction with clinical genetic test reports. ${ }^{14}$ This is likely due partly to variation in reporting of molecular genetic test results. ${ }^{15}$ Regulatory requirements and professional standards have been developed with the goal to improve genetic test reporting. The Clinical Laboratory Improvement Amendments specify criteria to be included in the clinical test result, but they do not provide guidance for effectively communicating these elements. ${ }^{16}$ Other groups provide guidance describing how to report results for certain conditions (e.g., rare genetic disorders) or types of tests (e.g., DNA sequencing) ${ }^{17-20}$ that are of value in crafting reports for the purposes for which they were

${ }^{1}$ RAND Corporation, Santa Monica, California, USA; ${ }^{2}$ Department of Veterans Affairs, Greater Los Angeles Healthcare System, Los Angeles, California, USA; ${ }^{3}$ Department of Medicine, David Geffen School of Medicine, University of California, Los Angeles, Los Angeles, California, USA; ${ }^{4}$ Quest Diagnostics, West Hills, California, USA; ${ }^{5}$ Department of Pathology and Laboratory Medicine, David Geffen School of Medicine, University of California, Los Angeles, Los Angeles, California, USA; ${ }^{6}$ Division of Laboratory Sciences and Standards, Centers for Disease Control and Prevention, Atlanta, Georgia, USA. Correspondence: Maren T. Scheuner (maren.scheuner@va.gov) 
developed. Yet these guidelines do not fully consider the needs of the end-user in providing a format for effective communication of clinically actionable information.

Previously, we created a molecular genetic test report template suitable for a broad range of molecular genetic tests designed to mitigate postanalytic errors in the genetic testing process. ${ }^{21}$ The report template uses the combined features of synoptic reporting and narrative interpretation. The template includes data element grouping and report design recommendations, including the preferred order of report sections (patient and physician information, test performed, test results and interpretation, guidance on next steps, and supplemental information), formatting of data, and the report length. This study sought to determine whether a report generated with this template could improve satisfaction, ease of use, effectiveness to communicate various aspects of the report, and effectiveness to make medical decisions, as compared with standard reports generated by commercial and academic molecular genetic laboratories.

\section{MATERIALS AND METHODS}

Two clinical scenarios were created to inform the development of molecular genetic test reports: a 40-year-old man with pulmonary embolism who is heterozygous for a factor V Leiden (FVL) mutation and a 40-year-old man with colon cancer whose tumor shows lack of staining for the MLH1 protein and who is heterozygous for a frameshift mutation in the MLH1 gene, which is diagnostic of Lynch syndrome. These scenarios were selected because both are potentially frequently encountered by primary care providers caring for adult patients. For these clinical scenarios, six clinical molecular genetic laboratories (four commercial and two academic) in the United States created three reports for FVL (Supplementary Figures S1-S3 online) and three reports for Lynch syndrome (Supplementary Figures S4-S6

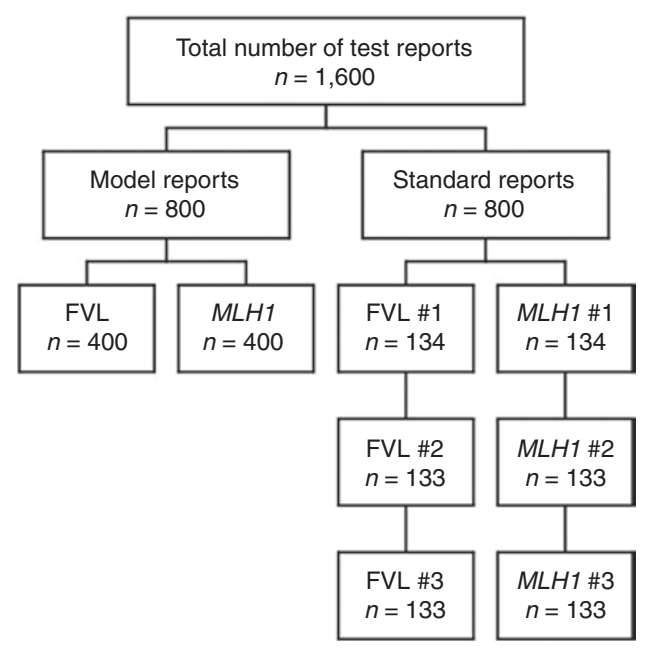

Figure 1 A survey was mailed to 1,600 office-based, family practice or general internal medicine physicians. Half received a factor $\vee$ Leiden report and half received an MLH1 (Lynch syndrome) report, with equal proportions of model reports developed using the template and standard reports developed by clinical laboratories. online) referred to as the standard reports, and the research team developed a report for each scenario using the report template, referred to as the model reports (Supplementary Figures S7-S8 online). Two commercial laboratories and one academic laboratory developed the standard FVL reports;

Table 1 Characteristics of survey respondents $(n=384)$

\begin{tabular}{|c|c|c|}
\hline & $n$ & $\%$ \\
\hline \multicolumn{3}{|l|}{ Gender } \\
\hline Male & 258 & 67.2 \\
\hline Female & 123 & 32.0 \\
\hline Missing & 3 & 0.8 \\
\hline \multicolumn{3}{|l|}{ Age group } \\
\hline$<30$ years & 2 & 0.5 \\
\hline $30-50$ years & 200 & 52.1 \\
\hline $51-65$ years & 144 & 37.5 \\
\hline$>65$ years & 37 & 9.6 \\
\hline Missing & 1 & 0.3 \\
\hline \multicolumn{3}{|l|}{ Specialty } \\
\hline Internal medicine & 165 & 43.0 \\
\hline Family practice & 213 & 55.5 \\
\hline Both internal medicine and family practice & 6 & 1.5 \\
\hline \multicolumn{3}{|l|}{ Year graduated from medical school } \\
\hline 1937-1979 & 92 & 24.0 \\
\hline 1980-1986 & 84 & 21.9 \\
\hline 1987-1995 & 97 & 25.3 \\
\hline 1996 and later & 102 & 26.5 \\
\hline Missing & 9 & 2.3 \\
\hline \multicolumn{3}{|l|}{ Time spent in direct patient care in past year } \\
\hline$<10 \%$ & 8 & 2.1 \\
\hline $11-50 \%$ & 18 & 4.7 \\
\hline$>50 \%$ & 355 & 92.4 \\
\hline Missing & 3 & 0.8 \\
\hline \multicolumn{3}{|l|}{ Number of years in clinical practice } \\
\hline $1-10$ & 87 & 22.7 \\
\hline $11-20$ & 132 & 34.4 \\
\hline $21-30$ & 103 & 26.8 \\
\hline$>30$ & 62 & 16.1 \\
\hline \multicolumn{3}{|c|}{ Number of molecular genetic tests ordered or reviewed in past year } \\
\hline None & 137 & 35.7 \\
\hline $1-10$ & 184 & 47.9 \\
\hline $11-50$ & 56 & 14.6 \\
\hline $51-100$ & 4 & 1.0 \\
\hline$>100$ & 1 & 0.3 \\
\hline Missing & 2 & 0.5 \\
\hline
\end{tabular}

There were 396 respondents; however, eight were excluded because they did not select internal medicine or family practice as a specialty area, and another four were excluded because $>50 \%$ of their responses were missing. A total of $27 \%$ graduated medical school after 1995, 92\% spend more than half their time in direct patient care, and $36 \%$ had not ordered a genetic test in the past year. 
they were two pages in length. Two commercial laboratories and one academic laboratory developed the standard Lynch syndrome reports, which varied in length at one, two, and three pages. The commercial laboratories used their templates for electronic report transmission, whereas the academic laboratories used their templates to develop a hard copy that would be transmitted by mail or fax. The name of the fictitious laboratory on all of the reports was "The Genetics Laboratory" located in "Nowhere, State," and the name of the fictitious ordering clinician was "Dr. Good."

An 18-item survey was developed to assess the standard and model reports. The survey items were informed by focusgroup experiences with primary care providers from the Los Angeles, Washington, DC, and Chicago areas. ${ }^{21}$ The survey questions addressed satisfaction (three items), ease of use (five items), effectiveness to communicate different aspects of the report (five items), effectiveness to inform medical decisions, and understanding of the genetic test results (five items). A four-point scale was used for the response options to these questions, ranging from "not at all" to "very" satisfied, easy, or effective. Seven additional items asked about respondent characteristics, including age, gender, year of graduation from medical school, percent of time spent in direct patient care in the past 12 months, number of years in clinical practice, specialty, and number of molecular (DNA or RNA) genetic tests ordered or reviewed in the past year.

Survey respondents were selected from the American Medical Association Masterfile and included 1,600 officebased, primary care physicians (800 general internal medicine and 800 family practice) from the United States. The survey and one of the standard or model reports were mailed to these physicians; this included 400 model reports and 400 standard reports for both FVL and Lynch syndrome (Figure 1). The first mailing included a $\$ 5$ cash incentive, and there were two follow-up mailings to nonrespondents without a cash incentive.

Descriptive statistics were used to characterize the survey respondents. Factor analysis was used to identify subscales in the responses. Analysis of variance was used to test for differences in responses between the standard reports. Mean score differences between standard and model reports were compared using $t$-tests. Two-way analysis of variance was used to evaluate the effect of model versus standard reports and the influence of select demographic variables on mean scores.

The RAND Human Subjects Protection Committee approved all aspects of this study.

Table 2 Scores for the model and standard factor V Leiden mutation reports

\begin{tabular}{|c|c|c|c|c|}
\hline \multirow[b]{2}{*}{ Items } & \multicolumn{2}{|c|}{ Model report } & \multicolumn{2}{|c|}{ Standard report } \\
\hline & Mean & SD & Mean & SD \\
\hline \multicolumn{5}{|l|}{ How satisfied are you with the. } \\
\hline Amount of information in the report? & 3.36 & 0.69 & 3.20 & 0.76 \\
\hline Organization of the information in the report? & 3.35 & 0.67 & 3.17 & 0.71 \\
\hline Find information in the report to help with decision making? & 3.19 & 0.73 & 2.96 & 0.87 \\
\hline Understand the terminology used in the report? & 3.20 & 0.67 & 3.02 & 0.78 \\
\hline Understand the test result presented in the report? & 3.26 & 0.64 & 3.07 & 0.76 \\
\hline Understand the interpretation of the test result in the report? & 3.21 & 0.70 & 3.00 & 0.79 \\
\hline Guidance describing the implications of the test result? & 3.12 & 0.70 & 3.06 & 0.78 \\
\hline Availability of information resources for you? & 3.14 & 0.66 & 2.95 & 0.91 \\
\hline Availability of information resources for your patients? & 2.85 & 0.76 & 2.55 & 1.03 \\
\hline \multicolumn{5}{|l|}{ How effectively does the report inform your... } \\
\hline Medical decision making? & 3.11 & 0.69 & 2.99 & 0.75 \\
\hline Ability to communicate the implications of the test result? & 3.11 & 0.72 & 3.01 & 0.83 \\
\hline Understanding of the clinical issues relating to the result? & 3.12 & 0.66 & 3.01 & 0.80 \\
\hline Understanding of the genetic/hereditary aspects of the result? & 3.17 & 0.69 & 2.88 & 0.82 \\
\hline Understanding of the limitations of the test result? & 2.95 & 0.77 & 2.84 & 0.80 \\
\hline
\end{tabular}


Table 3 Scores for the model and standard Lynch syndrome reports

\begin{tabular}{|c|c|c|c|c|}
\hline \multirow[b]{2}{*}{ Items } & \multicolumn{2}{|c|}{ Model report } & \multicolumn{2}{|c|}{ Standard report } \\
\hline & Mean & SD & Mean & SD \\
\hline \multicolumn{5}{|l|}{ How satisfied are you with the ... } \\
\hline General format (look and feel) of the report? & 3.23 & 0.58 & 2.73 & 0.77 \\
\hline Amount of information in the report? & 3.31 & 0.66 & 2.80 & 0.86 \\
\hline Organization of the information in the report? & 3.28 & 0.62 & 2.80 & 0.82 \\
\hline \multicolumn{5}{|l|}{ How easy is it to ... } \\
\hline Find the test result in the report? & 3.19 & 0.78 & 2.72 & 0.96 \\
\hline Find information in the report to help with decision making? & 3.15 & 0.75 & 2.56 & 0.92 \\
\hline Understand the terminology used in the report? & 2.94 & 0.80 & 2.13 & 0.93 \\
\hline Understand the test result presented in the report? & 3.13 & 0.73 & 2.38 & 0.89 \\
\hline Understand the interpretation of the test result in the report? & 3.09 & 0.73 & 2.41 & 0.88 \\
\hline \multicolumn{5}{|l|}{ How effectively does the report communicate... } \\
\hline The test result? & 3.28 & 0.69 & 2.81 & 0.87 \\
\hline The interpretation of the test result? & 3.23 & 0.69 & 2.63 & 0.86 \\
\hline Guidance describing the implications of the test result? & 3.17 & 0.73 & 2.55 & 0.83 \\
\hline Availability of information resources for you? & 3.16 & 0.66 & 2.44 & 0.90 \\
\hline Availability of information resources for your patients? & 2.99 & 0.73 & 2.08 & 0.97 \\
\hline \multicolumn{5}{|l|}{ How effectively does the report inform your ... } \\
\hline Medical decision making? & 3.12 & 0.74 & 2.45 & 0.82 \\
\hline Ability to communicate the implications of the test result? & 3.11 & 0.78 & 2.37 & 0.85 \\
\hline Understanding of the clinical issues relating to the result? & 3.21 & 0.69 & 2.28 & 0.88 \\
\hline Understanding of the genetic/hereditary aspects of the result? & 3.19 & 0.69 & 2.48 & 0.95 \\
\hline Understanding of the limitations of the test result? & 2.88 & 0.80 & 2.51 & 0.91 \\
\hline Mean total score & 3.15 & 0.55 & 2.50 & 0.65 \\
\hline
\end{tabular}

\section{RESULTS}

There were 396 (24\%) survey respondents; however, eight were excluded because they did not select internal medicine or family practice as a specialty, and another four were excluded because $>50 \%$ of their responses were missing. Characteristics of the 384 respondents included in the analyses are shown in Table 1, including 93 who received the model FVL report, 99 who received one of the standard FVL reports, 104 who received the model Lynch syndrome report, and 88 who received one of the standard Lynch syndrome reports.

There were no significant associations between the gender and specialty of the respondent or whether the respondent ordered or reviewed any tests during the preceding year. There were no significant associations between specialty and the number of tests ordered or reviewed in the past year or recent medical school graduation (1996 or later). However, there were significant associations between recent medical school graduation and female gender $(P<0.0001)$, and recent graduation and having ordered or reviewed at least one molecular genetic test $(P=0.02)$.

Factor analysis showed there was no evidence of subscales in the survey responses; the 18-survey items reflected a single dimension. Therefore, the mean total score for each report type (model or standard) was deemed to be best for comparing the reports. No significant differences were observed among the three standard FVL reports or among the three standard Lynch syndrome reports. Therefore, the model reports were compared with a composite of the standard reports for each item on the survey, as well as the mean of the total score for all items.

The mean scores for the model versus standard FVL and Lynch syndrome reports are shown in Tables 2 and 3, respectively. For each of the 18-survey items, the model reports had greater scores than the standard reports. The mean total scores were significantly greater for both model reports as compared with the standard reports. The mean total scores for the FVL model versus standard reports were $3.19(\mathrm{SD}=0.52)$ and 3.00 $(\mathrm{SD}=0.62)$, respectively $(P=0.028$; effect size $=0.322)$. The mean total scores for the Lynch syndrome model and standard reports were $3.15(\mathrm{SD}=0.55)$ and $2.50(\mathrm{SD}=0.65)$, respectively $(P<0.0001$; effect size $=1.08)$. Of note, the mean total scores for the FVL and Lynch syndrome model reports were similar at 3.15 and 3.19 , respectively.

Gender and specialty of the respondent were not associated with the mean total scores, and there was no interaction 


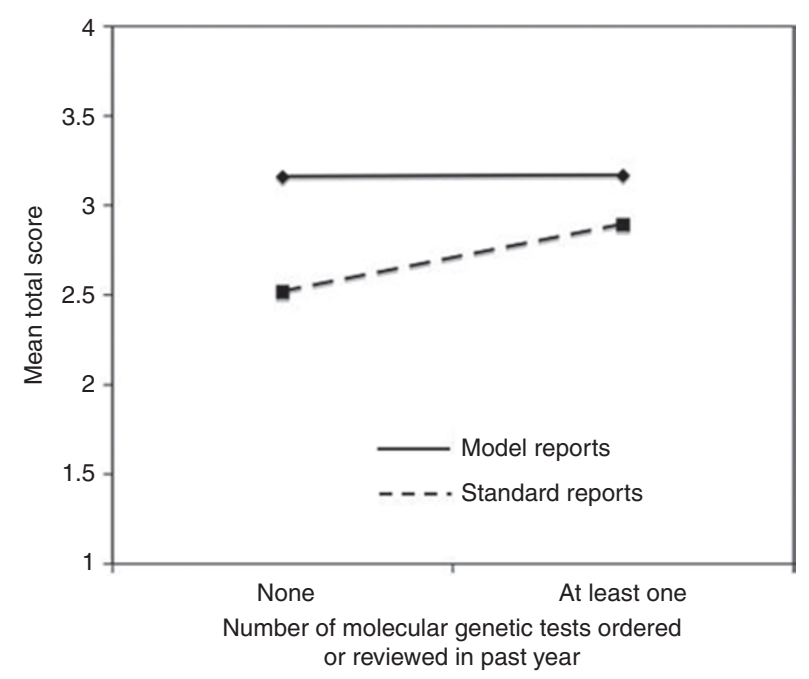

Figure 2 The mean total scores for the model reports $(0.01,3.17-3.16)$ developed using the template were substantially different for the standard reports $(0.37,2.89-2.52)$ developed by clinical laboratories, with a significant interaction between the type of report (model versus standard) and the number of tests (none versus at least one) ordered or reviewed in the past year, $P=0.005$

between gender or specialty and the type of report (i.e., model or standard). Recent medical school graduates (1996 and later) gave significantly higher scores than graduates from prior years (3.12 and 2.93, respectively; $P=0.01$ ), regardless of report type (i.e., there was no interaction between report type and year of graduation). Figure 2 shows the differences in mean total scores for physicians who had ordered or reviewed at least one molecular genetic test report in the past year versus physicians who had not. The difference in mean total scores was not different for the model reports $(3.17-3.16=0.01)$ but was substantially different for the standard reports $(2.89-2.52=0.37)$, with a significant interaction between report type and number of tests ordered or reviewed in the past year $(P=0.005)$.

\section{DISCUSSION}

With our national survey of primary care physicians, we demonstrate that the use of a template designed to guide development of molecular genetic test reports in a standardized, synoptic fashion improved the satisfaction, ease of use, and the effectiveness in communicating genetic test results and in conveying information for clinical decision making based on those results, as compared with standard reports from six clinical laboratories. These six clinical laboratories used both electronic and paper-based formats; however, we found no differences between these report formats. However, the formatting in the template for the model reports (e.g., bold fonts, underline, bulleted text, and differing font sizes) may not be easily integrated within current laboratory information systems. Perhaps our findings might provide the impetus to improve the presentation quality of these systems.

Gender and specialty of the survey respondents had no effect on report ratings; however, younger physicians (recent medical school graduates) gave higher scores regardless of the type of report, possibly because of greater familiarity with genetics and genetic testing. Of note, our findings show that physicians least familiar with genetic test reports, and possibly having the greatest need for better communication of the results, were best served by the model reports that used the template.

The test requisition is another communication tool that can affect interpretation of the test result by the laboratory and clinician. For heritable genetic conditions that are often rare, ordering the right test can be challenging for clinicians without expertise in genetics. The genetic test requisition can serve as an important tool that can help in the selection of the right test for the right patient through the collection of patient information, including medical history, ancestry, and family history. Integrating this patient information is essential to the accurate interpretation of most test results, and failing to do so can compromise the usefulness of the test report. Therefore, the most optimal communication between the genetic testing laboratory and clinician should result from use of both effective test requisitions and reports.

There are several strengths and limitations of this study that deserve mention. The use of a national sample of primary care providers is a strength. We had a $24 \%$ response rate, which was large enough to detect significant differences between the model and standard reports, but the sample was not large enough to detect certain subgroup differences. Our survey was restricted to office-based, primary care physicians (general internal medicine and family practice); therefore, our findings may not be generalizable to other types of clinicians or clinicians practicing in other settings. However, primary care physicians comprise the largest aspect of the health-care system in the United States, ${ }^{22}$ and they will likely be ordering an increasing number of genetic tests. ${ }^{23-25}$ Understanding their needs and preferences is important, particularly because evidence suggests they might be inadequately prepared to integrate genetic information and testing applications appropriately into routine practice. ${ }^{10-13,26,27}$ We only considered two clinical scenarios to evaluate the report template, heterozygosity for a FVL mutation and heterozygosity for an $M L H 1$ gene mutation causing Lynch syndrome. These scenarios were selected because they are relatively common heritable conditions that are likely to be seen by primary care physicians, particularly those caring for adult patients. The scenarios used provided a range of complexity relating to testing technologies (targeted mutation testing and sequencing) and their limitations, and the types of results expected. Therefore, our findings are likely generalizable to the spectrum of genetic tests ordered by most non-genetics professionals.

In summary, clinical care in the United States, and throughout the world, depends on clinical laboratories for essential diagnostic and therapeutic decisions. Laboratory testing is particularly essential for medical genetics, given the rapidly expanding portfolio of molecular tests for heritable conditions and markers of drug metabolism. Genetic test results for heritable conditions can be complex, with 
implications for clinical decision making, reproductive decision making, and life planning for both patients and their family members. Because these tests are complex and are typically performed only once in a person's lifetime, it is imperative that genetic test results are effectively communicated from the laboratory to clinicians and then to patients. We propose that using the template evaluated in this study conveys clinically useful information in an effective manner using a standardized approach that can serve as a model for genetic test reports for heritable conditions.

\section{SUPPLEMENTARY MATERIAL}

Supplementary material is linked to the online version of the paper at http://www.nature.com/gim

\section{ACKNOWLEDGMENTS}

This work was supported by a cooperative agreement from the Centers for Disease Control and Prevention. The authors thank the RAND staff who supported this project, including Suzanne Benedict, Kristin Leuschner, PhD, Chau Pham, MS, Julie Brown, and Diane Schoeff. The authors thank the members of the RAND Molecular Genetic Test Report Advisory Board: Jean Amos Wilson, PhD, Joanne Armstrong, MD, Sylvia Au, MS, CGC, Dave Dotson, PhD, Laurel Estabrooks, PhD, Hawazin Faruki, DrPH, W. Andrew Faucett, MS, CGC, W. Gregory Feero, MD, PhD, Wayne Grody, MD, PhD, Mark Hoffman, PhD, Katherine A Johansen, PhD, Jeffrey A. Kant, MD, PhD, Howard Levy, MD, PhD, Elaine Lyon, PhD, Joseph D. Mclnerny, MA, MS, Harvey J. Murff, MD, MPH, Roberta A. Pagon, MD, Kate Reed, MS, CGC, Sue Richards, PhD, Wes Schreiber, MD, Iris Schriever, PhD, Tracy L. Trotter, MD, Bonnie Van, PhD, Neil S. Wenger, MD, MPH, Vicky Whittemore, PhD, Marc Williams, MD, Suzanne Ziemnik.

\section{DISCLOSURE}

The authors declare no conflict of interest.

\section{REFERENCES}

1. Khoury MJ, Yang Q, Gwinn M, Little J, Dana Flanders W. An epidemiologic assessment of genomic profiling for measuring susceptibility to common diseases and targeting interventions. Genet Med 2004;6:38-47.

2. Paynter NP, Chasman DI, Paré G, et al. Association between a literature-based genetic risk score and cardiovascular events in women. JAMA 2010;303: 631-637.

3. Meigs JB, Shrader P, Sullivan LM, et al. Genotype score in addition to common risk factors for prediction of type 2 diabetes. N Engl J Med 2008;359: 2208-2219.

4. Palomaki GE, Melillo S, Neveux L, et al. Use of genomic profiling to assess risk for cardiovascular disease and identify individualized prevention strategies-a targeted evidence-based review. Genet Med 2010;12: 772-784.
5. Bonini P, Plebani $\mathrm{M}$, Ceriotti F, Rubboli F. Errors in laboratory medicine. Clin Chem 2002;48:691-698.

6. Plebani M. Errors in clinical laboratories or errors in laboratory medicine? Clin Chem Lab Med 2006;44:750-759.

7. Carraro P, Plebani M. Errors in a stat laboratory: types and frequencies 10 years later. Clin Chem 2007;53:1338-1342.

8. Kirchner MJ, Funes VA, Adzet CB, et al. Quality indicators and specifications for key processes in clinical laboratories: a preliminary experience. Clin Chem Lab Med 2007;45:672-677.

9. Sandhaus LM, Singer ME, Dawson NV, Wiesner GL. Reporting BRCA test results to primary care physicians. Genet Med 2001;3:327-334.

10. Suther S, Goodson P. Barriers to the provision of genetic services by primary care physicians: a systematic review of the literature. Genet Med 2003;5:70-76.

11. Burke W, Culver J, Pinsky L, et al. Genetic assessment of breast cancer risk in primary care practice. Am J Med Genet A 2009;149A:349-356.

12. Brierley KL, Campfield D, Ducaine W, et al. Errors in delivery of cancer genetics services: implications for practice. Conn Med 2010;74:413-423.

13. United Healthcare Center for Health Reform \& Modernization. Personalized medicine: Trends and prospects for the new science of genetic testing and molecular diagnostics. Working Paper 7. http://www.unitedhealthgroup.com/ hrm/UNH_WorkingPaper7.pdf Accessed 6 May 2012.

14. Krousel-Wood M, Andersson HC, Rice J, Jackson KE, Rosner ER, Lubin IM. Physicians' perceived usefulness of and satisfaction with test reports for cystic fibrosis (DeltaF508) and factor V Leiden. Genet Med 2003;5:166-171.

15. Andersson HC, Krousel-Wood MA, Jackson KE, Rice J, Lubin IM. Medical genetic test reporting for cystic fibrosis (deltaF508) and factor $V$ Leiden in North American laboratories. Genet Med 2002;4:324-327.

16. Medicare, Medicaid, and CLIA programs; laboratory requirements relating to quality systems and certain personnel qualifications. Final rule. Fed Regist 2003;68:3639-3714.

17. American College of Obstetrics and Gynecology. Preconception and Prenatal Carrier Screening for Cystic Fibrosis. Clinical and Laboratory Guidelines. Washington, DC: American College of Obstetrics and Gynecology (ACOG) 2001

18. NCCLS. Nucleic acid sequencing methods in diagnostic laboratory medicine; approved guideline. In: Institute CaLS, ed. vol. 24. NCCLS: Wayne, PA, 2004.

19. Gulley ML, Braziel RM, Halling KC, et al. Clinical laboratory reports in molecular pathology. Arch Pathol Lab Med 2007;131:852-863.

20. Maddalena A, Bale S, Das S, Grody W, Richards S. Technical standards and guidelines: molecular genetic testing for ultra-rare disorders. Genet Med 2005;7:571-583.

21. Scheuner MT, Hilborne L, Brown J, Lubin IM; members of the RAND Molecular Genetic Test Report Advisory Board. A report template for molecular genetic tests designed to improve communication between the clinician and laboratory. Genet Test Mol Biomarkers 2012;16:761-769.

22. National Center for Health Statistics. Health, United States, 2010: With Speical Feature on Death and Dying. Hyattsville, MD, 2011.

23. Greendale K, Pyeritz RE. Empowering primary care health professionals in medical genetics: how soon? How fast? How far? Am J Med Genet 2001;106:223-232.

24. Khoury MJ. Genetics and genomics in practice: the continuum from genetic disease to genetic information in health and disease. Genet Med 2003;5:261-268.

25. Feero WG. Genetics of common disease: a primary care priority aligned with a teachable moment? Genet Med 2008;10:81-82.

26. Doksum T, Bernhardt BA, Holtzman NA. Does knowledge about the genetics of breast cancer differ between nongeneticist physicians who do or do not discuss or order BRCA testing? Genet Med 2003;5:99-105.

27. Scheuner MT, Sieverding P, Shekelle PG. Delivery of genomic medicine for common chronic adult diseases: a systematic review. JAMA 2008;299:13201334. 